\title{
An Empirical Examination Of The Effects Of Inflation And Hedging On Investments In The U.S. Air Transport Sector Over The Period Since Deregulation
}

\author{
Bahram Adrangi, (E-mail: adrangi@up.edu), University of Portland \\ George Battistel, (E-mail: battistel@up.edu), University of Portland \\ Arjun Chatrath, (E-mail: chatrath@up.edu), University of Portland \\ Richard Gritta, (E-mail: gritta@up.edu), University of Portland \\ Kambiz Raffiee, (E-mail: raffiee@unr.edu), University of Nevada, Reno
}

\begin{abstract}
Research in economics and finance has documented a negative relationship between stock returns and inflation rates in most economies. The purpose of this study is to investigate this relationship for a particular specific sector investment, air transportation. A significant negative relationship is shown between the air equity index returns and unexpected inflation. Air equity returns, however, are found not be correlated with expected inflation. The Johansen and Juselius cointegration tests verify a long-run equilibrium between air transport equity index, general price levels, and the real economic activity. The short-run dynamics derived from the error-correction model, however, do not support air transport equity index's long-run inflation hedging ability. These findings indicate that investing in air transport equity index may not be a reliable hedge against inflation in the long- or short-run. In addition, the findings do not lend support for the Fisherian and Proxy hypotheses.
\end{abstract}

\section{INTRODUCTION}

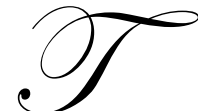

he relationship between asset prices and inflation has intrigued researchers over the past several decades. Historically, a negative relationship has existed between stock prices and inflation. During the rapid inflation years of 1970s, for example, U.S. stocks prices did not keep pace with general price levels. Lintner (1975), Fama and Schwert (1977), Nelson (1976), Jaffe and Mandelker (1979), Fama (1981, 1982), Geske and Roll (1983), and Wahlroos and Berglund (1986), among others, found evidence that stock returns are negatively affected by both expected and unexpected inflation in the U.S. More recently, Serletis (1993) and Thornton (1993) investigated a related issue of stock prices and money supply in the U.S. and UK.

The purpose of this paper is to investigate this relationship in the air transport sector. The study examines the relationship between the air transport stock price index (PR) returns and inflation in the U.S. The forces of supply (cost-side) and demand (revenue-side) for air travel ultimately affect air transport stock prices. Many factors may affect the supply and demand for air transport services (Adrangi, Chow and Raffiee, 1996 and 1999). On the supplyside, labor, fuel and aircraft leases or acquisitions are the major determinants of the costs of airlines. On the demandside, average passenger yield, average freight yield and load factor are the major determinants of the revenues of airlines. Air transportation equity prices are chosen in order to extend previous research findings to a service related equity index. It is interesting to examine a key service sector of the economy while most other studies are concerned with real assets, or securitized versions of real assets. 
The study contributes to the literature in several ways. First, the findings of this investigation should be important to many groups including portfolio managers, airline management, labor, regulators and other interested parties. Portfolio managers and analysts in popular media and investment letters often recommend air transport investment for short and long-term investors. It is important to establish this property empirically. Furthermore, it is valuable to determine whether investment in this sector is a valid hedge instrument during inflationary periods as well as unanticipated rises in general price levels. In addition, the relationship tested should be of primary concern to airline management and labor that have retirement accounts heavily invested in their employers' stocks. Economic policy makers and regulators should also be concerned because of the significant problems airlines have encountered with their defined benefit pension plans.

Second, it is informative to investigate the relationships between the air transport equity index and inflation in light of the proxy hypothesis. The proxy hypothesis is an explanation for the negative relationship between stock returns and inflation. The investigation of the proxy hypothesis for this sector may further shed light on the possibility of using air transport sector investments as an inflation hedge. Furthermore, as was discussed above, the fundamentals affecting the demand for air transport services may be both real economic activities and seasonal or cyclical factors. In this sense, the proxy hypothesis is a relevant framework to study air equity price fluctuations. If, for example, inflationary pressures cause a slow down in real economic activity, the final demand for air transport services (assuming no change in supply) may fall or stay neutral. The direction of the change in demand depends on the weight of the effects of the inflation on the real economic activity and inflationary fears.

Third, the paper also proposes a test for the Fisherian hypothesis. The Fisherian hypothesis argues that real returns in efficient markets are determined by real economic factors. ${ }^{1}$ According to Fisher (1930) asset values should be positively related with expected inflation, providing a hedge against rising prices. If the implied positive relationship between asset prices and the inflation does not hold, asset holders will be vulnerable to inflation. The implication of the Fisherian hypothesis for the air transport equity index is that real returns are expected to be uncorrelated with the expected inflation. The investigation of air transportation equity prices should also serve to highlight the differences in various investment vehicles or sector investments in the face of inflationary pressures. Finally, the study also examines the relationship between air transport stock index prices, inflation rate, and the real economic activity employing cointegration tests. The traditional regression equations may be unable to capture longrun relationships among these variables.

The remainder of this paper is organized as follows. Section II presents a literature review. Section III outlines the theoretical background. Data sources and the proposed empirical models are discussed in Section IV. The empirical findings and their analysis are the subject of Section V. Section VI provides a brief summary and conclusions.

\section{LITERATURE REVIEW}

Fama (1981) and Geske and Roll (1983) offer an explanation for the negative relationship between stock returns and inflation, through a hypothesized chain of macroeconomic linkages, based on the money demand and the quantity theory of money. There is some evidence that the negative relationship between inflation and stock returns in most markets results from a so called "proxy hypothesis" (see Fama (1965)). According to this hypothesis, the negative relationship between stock returns and the inflation reflects the deleterious effects of the inflation on the real economic activity.

Whether stocks also provide a hedge against inflation empirically has been studied extensively in the literature, see e.g. Fama (1981), Fama and Schwert (1977), Gultekin (1983), Boudoukh and Richardson (1993), Ely and Robinson (1997) and Barnes, Boyd and Smith (1999). With the only exception of Ely and Robinson (1997), the literature has based its inference on return regressions where nominal stock returns are regressed on inflation and possibly further explanatory variables such as real production growth and changes in a relevant discount rate measure. The inflation hedge hypothesis is examined by testing whether the coefficient to inflation is significant and equal to 1 . Results of the literature are fairly mixed, but a general conclusion is that stocks do not hedge against inflation in the short run (investment horizons less 
than 1-2 years), where inflation usually turns out to have an insignificant effect on stock returns. In fact, at short horizons the estimated relation between nominal stock returns and inflation may even be negative, see e.g. Fama and Schwert (1977) and Gultekin (1983). There is some evidence of a significant positive relationship on longer horizons (more than 2 years) but often with a coefficient different from 1 so that the inflation hedge is not perfect, see Boudoukh and Richardson (1993). Hence, the hedge hypothesis comes closer to receiving support at longer horizons but the evidence is still weak. On balance, it seems that the empirical evidence tends to reject the hypothesis of stocks providing a (perfect) hedge against inflation.

Olesen (2000) provides an alternative approach to testing whether stocks provide a hedge against inflation in the long run applying cointegration analysis. Using data for the Danish stock market over the post-World War IIperiod, results give strong support for the hedge property, defined in the narrow sense of a perfect hedge. This contrasts with the weak support found in the literature and also represents stronger support than produced by standard methods. Almost all papers reviewed employ aggregate stock index returns in their empirical tests. Aggregation and weighting process in developing stock indices for the entire economy may cast some doubt on empirical findings. Industry studies or even disaggregated firm level data requires further investigation on inflation hedging and equity performance.

Other researchers have examined individual commodities or assets as hedge against inflation. Christie-David et al. (2000) examined gold and silver futures, and Mahdavi and Zhou (1997) found that the London price of gold and the CPI are not cointegrated. Feldstein $(1980 \mathrm{~b})$ examined the traditional theory that the relative prices of consumer goods and real assets such as land and gold should not be affected by the inflation rate, concluding that in the decade of 1970s, prices of store of value assets such as gold increased substantially more than the general price level. Thus, gold was a safe haven against inflation. Larsen and McQueen (1995) studied the similarities and differences in the behavior of various assets and their securitized form such as REIT and real estate or gold and gold stocks. They concluded that gold performs well as an inflation hedge. However, they also noted that gold stocks, which are a securitized form of this type of asset, are not necessarily good hedging vehicles.

\section{THE THEORETICAL FRAMEWORK}

Two alternative theoretical frameworks are offered in this section. The first is related to Fama's proxy hypothesis. This explanation may be summarized as: (i) in the long run there is a negative relationship between inflation and real economic activity; and (ii) equity returns are directly related to the real economic activity. Based on (i) and (ii), the Fama, Geske, and Roll hypothesis predicts that rising inflation rates reduce real economic activity and demand for money. ${ }^{2}$ A reduction in economic activity negatively affects the future corporate profits and stock prices. $^{3}$

To be more specific, the PR responds to supply and demand fundamentals in the air transport sector. It is well documented in the academic and popular literature that air transport supply and demand fundamentals are dependent on the general levels of economic activity, which tend to change over time. On the demand side there are changing consumer sentiments and fluctuations in air travelers' income. These factors coupled with economic cycles and changes in the telecommunication technology create instability in the demand for business travel. Because of this the negative effects of inflation on the real economic activity lead to a reduction in the business and leisure demand for air travel. A decrease in demand, cetris paribus, leads to a fall in air transport equity index. On the supply side, marginal costs of all major air carriers have shifted up, leading to significant cost increases. For example, during the decade of $90 \mathrm{~s}$, major carriers negotiated expensive labor contracts. These contracts required higher fares for carriers to make a profit. With the economic growth and equity market rise of 1990s, this was not a problem. With the slow down in the economy starting in the late 1990s, major carriers faced falling revenues and expensive long-term labor contracts. To complicate matters, analysts believe that even the business demand for air travel has permanently changed. Business travelers, in the era of cost cutting, use the Internet and the fare transparency it has created to their advantage. Thus, the prediction is that even if demand rises, major carriers are not going to be able to exercise price discrimination models to recover high costs of doing business. ${ }^{4}$ 
For empirical purposes, this paper examines the role of air transportation equity index as an inflation hedge by testing (a) the relationship between inflation and real economic activity, (b) air transport equity index returns and the real economic activity, and finally (c) a joint test of air index returns.

The following further supports the empirical approach theoretically. The possible negative relationship between the inflation and real economic activity is based on shifts in the Phillips curve. The Phillips curve shows the relationship between a measure of real economic activity, such as the rate of growth of real output or unemployment, and a nominal variable, such as the inflation rate. According to the Phillips curve, higher rates of unemployment are associated with lower inflation rates and vice versa. ${ }^{5}$ It is well documented that the Phillips curve shifts to the right as inflationary expectations are formed. The shift occurs as demand for higher nominal wages reduce employment at any given inflation rate. That is, higher inflation rates may be associated with lower real economic activity because of the inflationary spiral. An alternative explanation for the same phenomenon may be derived from the Keynesian view. Higher rates of inflation may stunt new investments, thus reducing both the aggregate demand and aggregate supply, causing real output may fall. The positive relationship between the real economic activity and the demand for equities is more obvious and plausible. The increased real economic activity is likely to contribute to an increased business and individual demand for air travel and, thus, rising air transport equity index. Based on the above explanations, it is reasonable to assume that inflation and real economic activities may be considered exogenous, and real PR returns endogenous variables in empirical models for this study.

\section{DATA AND EMPIRICAL MODELS}

The period of this study covers from September 1979 through December 1998, to focus on the postderegulation era for the industry in the U.S. ${ }^{6}$ Monthly values of air transport equity index is used to compute returns. ${ }^{7}$ The index of industrial production is selected as a proxy for the real economic activity. Both the industrial production index (IP) and the consumer price index (CPI) are taken from the CRSP database.

Prior to testing the relationship between inflation and PR returns with the real economic activity, the negative relationship between real-returns and inflation is investigated. Economic agents and capital markets anticipate some portion of the inflation, but the unanticipated portion of the inflation rate may surprise equity markets and affect real returns. The Fisherian hypothesis for asset returns, which addresses these issues, is expressed in Fama and Schwert (1977). The empirical test of this hypothesis may be accomplished by estimating

$R_{t}-I N F_{t}=\alpha+\beta\left(\operatorname{EINF}_{t} \mid \Omega_{t-1}\right)+$ error $_{t}$,

where $R_{t}-I N F_{t}$ is the real return, the difference between the nominal return, $R_{t}$, and the inflation rate, INF , $E I N F_{t}$, is the expected inflation, $\Omega_{t-1}$, is the information set available at the time period t -1 , and the error term is randomly and normally distributed with zero mean and constant standard deviation. However, equities and bonds are claims against real assets and are often considered a potential hedge against unexpected as well as expected inflation. The following extension of equation (1) which, includes the unexpected inflation rate may be a more appropriate formulation of the Fisherian hypothesis:

$$
\begin{aligned}
& R_{t}-I N F_{t}=\alpha_{1}+\beta_{1}\left(E I N F_{t} \mid \Omega_{t-1}\right)+\beta_{2}\left(U_{I N F_{t}} \mid \Omega_{t-1}\right)+\text { error }_{t} . \\
& R_{t}-I N F_{t}=\alpha+\beta_{1}\left(I N F_{t} \mid \Omega_{t-1}\right)+\text { error }_{t}
\end{aligned}
$$

In Equations (2), the UINF is the INF-EINF. In the Fama and Schwert (1977) framework, air transport equity investment is a hedge against expected inflation if $\beta_{1} \geq 0$ and a perfect hedge against expected and unexpected inflation if $\beta_{1} \geq$ and $\beta_{2} \geq 0$, which would support the Fisherian hypothesis. ${ }^{8}$ A number of researchers 
have rejected the first, and often, both of these hypotheses. ${ }^{9}$ The outcome of empirical tests of the Fisherian hypothesis sets the stage for the remainder of the empirical work in this paper.

To investigate the interaction between the inflation real economic activity and the effects of the industrial demand on index returns, relationships expressed as (i) and (ii) are tested separately by estimating the following set of equations

$$
\begin{aligned}
& I N F_{t}=\alpha+\sum_{i=-k}^{k} \psi_{i} G I P_{t+i}+\varphi D_{t}+\text { error }_{t} \\
& R_{t}-I N F_{t}=\delta+\sum_{i=-k}^{k} \gamma_{i} G I P_{t+i}+\varphi D_{t}+\text { error }_{t},
\end{aligned}
$$

where all variables are defined as before, and GIP represents the growth rate in economic activity as measured by the industrial production. The leads and lags of GIP are included as explanatory variables due to the absence of a theory and any a priori evidence that inflation and real returns lead the economic activity. The dummy variable, $D_{t}$ takes values of one for 1979 through 1990 when prices levels were volatile and inflation rates higher than the rest of the period and zero otherwise. It is included in equations (4) and (5) to capture the possible effects of changes in inflationary pressures on real returns. In equations (4) and (5) negative $\psi_{i}$ and positive $\gamma_{i}$ coefficients would suggest that (i) there is a negative relationship between inflation and the industrial activity, and (ii) changes in real economic activity are directly related to the real returns of PR.

Equations (4) and (5) are estimated by OLS method with Newey-West heteroscedastic and autocorrelation consistent covariance matrix (Newey and West (1987)). ${ }^{10}$ The regression method rather than a vector autoregressive system is employed because the objective of the study is to isolate the relationship between PR returns, inflation, and the real economic activity. ${ }^{11}$

To derive the expected and unexpected components of the inflation rate two commonly used statistical approaches are utilized because series for expected inflation rate is often unavailable in developing economies. The first method involves the use of Hodrick-Prescott (HP) filter, suggested by Hodrick and Prescott (1980). This filter decomposes a series, $x$, into its trend and unexpected deviations from the trend. The second method requires finding the appropriate ARIMA models. The objective is to use the white noise residuals of the ARIMA model and treat them as the unexpected component of the series under question. The objective of this step is to verify the robustness of the statistical results derived from the HP Filter.

Only the results of HP will be reported in the interest of brevity. However, the results from ARIMA models are qualitatively identical to those obtained using HP filter. The HP filter requires minimizing

$$
\sum_{t=0}^{T}\left(x_{t}-\bar{x}_{t}\right)^{2}+\theta \sum_{t=0}^{T-1}\left[\left(\bar{x}_{t+1}-\bar{x}_{t}\right)-\left(\bar{x}_{t}-\bar{x}_{t-1}\right)\right], \text { for } \theta>0 .
$$

The technique allows for a stochastic trend component while deriving the temporary or unexpected component. ${ }^{12}$ Under the assumption that market participants form rational expectations regarding inflationary trend, the off-trend or temporary portion of the series may be considered the unexpected inflation.

The index returns are the percentage change in the air transport equity index, $\mathrm{R}_{t}=\mathrm{Ln}\left(\mathrm{PR}_{t} / \mathrm{PR}_{t-1}\right)$, where $\mathrm{PR}$ is the index value. The inflation rate and growth rate in industrial production are also computed in a similar manner. All variables are initially tested for stationarity by both the Augmented Dickey-Fuller (ADF, Dickey and Fuller (1979)) and Phillips-Perron (PP, Phillips and Perron (1990)) tests. 


\section{EMPIRICAL RESULTS}

This section reports the findings of the empirical tests of Fisher relationship between PR returns and inflation and the relationships between (i) inflation and industrial production and (ii) real PR returns and the industrial production. In order to avoid spurious regression results, all variables of the models are initially tested for unit roots.

\section{Unit Root Tests}

Table 1 reports the findings of the ADF and PP tests of unit roots. Panel A and B present unit root test results for level series and their percentage changes, respectively. The ADF test entails estimating $\Delta \mathrm{x}_{t}=\alpha+\beta \mathrm{x}_{t-1}+\sum_{j=1}^{L}$ $\gamma_{j} \Delta \mathrm{x}_{t-j}+u_{t}$ and testing the null hypothesis that $\beta=0$ versus the alternative of $\beta<0$, for any $\mathrm{x}$. The lag length $\mathrm{j}$ in the ADF test regressions is determined by the Akaike Information Criterion (AIC). The PP test estimates $\Delta \mathrm{x}_{t}=\alpha+$

$\beta \mathrm{x}_{t-1}+u_{t}$ and tests the null hypothesis that $\beta=0$ versus the alternative of $\beta<0$. Three variations of the ADF and PP regressions are estimated; with intercept, trend and intercept, and neither trend nor intercept. The purpose of this approach is to insure that the test results are robust in the presence of drifts and trends. The PP test may be more appropriate if autocorrelation in the series under investigation is suspected. The statistics are transformed to remove the effects of autocorrelation from the asymptotic distribution of the test statistic. The formula for the transformed test statistic is given in Perron (1988). The lag truncation of the Bartlett Kernel in the PP test is determined by the Akaike Information Criterion (AIC). In both the ADF and PP tests the MacKinnon (1990) critical values are used. Accepting the null hypothesis means that the series under consideration is not stationary and a unit root is present.

Panel A of Table 1 shows that the CPI, IP, and PR are generally nonstationary in the level, however, the rate of inflation (INF) and its unexpected component (UINF), index returns (R), and the growth in industrial production (GIP) are all stationary by both the ADF and PP tests as reported in Panel B. The evidence of stationarity for the expected rate of inflation (EINF) is mixed. However, the ADF test consistently rejects the hypothesis of nonstationarity for this variable. These findings indicate that almost all variables employed in regressions below are stationary and would not cause spurious regression outcomes.

\section{Air Transport Equity Index Returns and Inflation}

Table 2 presents coefficient estimates of equations (1) through (3). The Instrumental Variables Technique is employed to avoid possible endogeniety bias in coefficient estimates. The coefficients of the expected inflation in columns (1) and (2) are statistically insignificant, indicating that real returns are not correlated with the expected inflation rate. This finding suggests that rising inflation rates have no effect on air carrier earnings and profits. The coefficient of the unexpected inflation rate is significant in equation (2) verifying that air transport investment may not be a reliable hedge against unexpected inflation. Equation (3) shows that the inflation rate and the real air transport equity returns are also negatively correlated suggesting that air transport investments may not be an appropriate investment during the inflationary periods. These finding do not show support for the Fisherian hypothesis, i.e., they imply that real air transport index returns and the inflation rate are negatively correlated. Thus, real returns are falling during inflationary periods. The coefficient of the dummy variable is statistically insignificant in all equations. This could be due to the fact that there was a short-lived blip in the air transport equity index during 1981-1982 and the dummy variable is capturing that effect. In the following section the relationship between real index returns, real economic activity, and inflation is investigated by examining Fama's explanation summarized in (i) and (ii). 
Table 1: Unit Root Tests

\begin{tabular}{|c|c|c|c|c|c|}
\hline \multicolumn{6}{|c|}{ Air Index } \\
\hline \multicolumn{3}{|c|}{ Panel A: Level Series } & \multicolumn{3}{|c|}{ Panel B: Percentage Change Series } \\
\hline Variable & ADF & PP & Variable & ADF & PP \\
\hline $\mathrm{CPI}_{a}$ & -2.34 & $-3.26^{* * *}$ & $\mathrm{INF}_{a}$ & $-4.35^{* * *}$ & $6.60^{* * * *}$ \\
\hline $\mathrm{CPI}_{b}$ & -2.58 & -2.91 & $\mathrm{INF}_{b}$ & $-4.99^{* * *}$ & $-7.86^{* * *}$ \\
\hline $\mathrm{CPI}_{c}$ & 3.71 & $10.56^{* * *}$ & $\mathrm{INF}_{c}$ & $-3.01^{* * * *}$ & $-3.95^{* * * *}$ \\
\hline $\mathrm{IP}_{a}$ & 1.41 & 2.02 & $\mathrm{EINF}_{a}$ & -1.65 & -1.73 \\
\hline $\mathrm{IP}_{b}$ & -2.05 & -1.57 & $\mathrm{EINF}_{b}$ & -3.14 & -1.73 \\
\hline $\mathrm{IP}_{c}$ & 2.72 & 3.83 & EINF $_{c}$ & $-1.66^{*}$ & -1.74 \\
\hline $\mathrm{PR}_{a}$ & -1.17 & -2.04 & $\mathrm{UINF}_{a}$ & $-8.00^{* * * *}$ & $-10.17^{* * * *}$ \\
\hline $\mathrm{PR}_{b}$ & -2.41 & -2.63 & $\mathrm{UINF}_{b}$ & $-7.98^{* * * *}$ & $-10.14^{* * * *}$ \\
\hline \multirow[t]{7}{*}{$\mathrm{PR}_{c}$} & 0.29 & 0.09 & $\mathrm{UINF}_{c}$ & $-8.02^{* * * *}$ & $-10.19^{* * * *}$ \\
\hline & & & $\mathrm{R}_{a}$ & $-7.79^{\text {**** }}$ & $-3.88^{* * * *}$ \\
\hline & & & $\mathrm{R}_{b}$ & $-7.78^{* * * *}$ & $-13.85^{* * *}$ \\
\hline & & & $\mathrm{R}_{c}$ & $-7.72^{* * * *}$ & $-13.88^{* * * *}$ \\
\hline & & & $\mathrm{GIP}_{a}$ & $-5.42^{* * * *}$ & $-14.09^{* * * *}$ \\
\hline & & & $\mathrm{GIP}_{b}$ & $-5.65^{* * * *}$ & $-15.21^{* * * *}$ \\
\hline & & & $\mathrm{GIP}_{c}$ & $-4.88^{* * * *}$ & $-14.43^{* * * *}$ \\
\hline
\end{tabular}

Notes: PR, IP, and CPI represent air carrier equity price index, industrial production and CPI in U.S, respectively. $\mathrm{R}=\log \left(\mathrm{PR} t_{t} / \mathrm{PR} t-1\right)$, $\mathrm{GIP}=\log \left(\mathrm{IP}_{t} / \mathrm{IP}_{t-1}\right)$, and $\mathrm{INF}=\log \left(\mathrm{CPI} t_{t} / \mathrm{CPI}_{t-1}\right)$ measure air transportation equity returns, growth in industrial production, and the inflation rate, respectively. The expected (EINF) and unexpected (UINF) rates of inflation are derived from the Hodrick-Prescot method. (a), (b), and (c), represent Augmented Dickey Fuller(ADF) and Phillips-Perron (PP) unit root tests with intercept, with trend and intercept and with neither trend nor intercept, respectively.

The ADF entails estimating $\Delta \mathrm{x}_{t}=\alpha+\beta \mathrm{x}_{t-1}+\gamma_{j} \Sigma_{j=1}^{k} \Delta \mathrm{x}_{t-j}+u_{t}$ and testing the null hypothesis that $\beta=0$ versus the alternative of $\beta<0$, for any $\mathrm{x}$. The number of lags on the right-hand-side of ADF regressions as suggested by AIC and SIC. The PP test requires estimating $\Delta \mathrm{x}_{t}=\alpha+\beta \mathrm{x}_{t-1}+u_{t}$ and testing the null hypothesis $\beta=0$ versus the alternative of $\beta<0$. The PP test may be more appropriate if autocorrelation in the series under investigation is suspected. Lag truncation for Bartlett-kernel in Phillips-Perron test are suggested by Newey-West.

$*, * *$, and $* * *$ represent $10 \%, 5 \%$, and $1 \%$ significance levels, respectively. 
Table 2: 2SLS estimates of air transportation equity index versus inflationary trends

$$
\begin{aligned}
& R_{t}-I N F_{t}=\alpha_{1}+\beta_{1} E I N F_{t}+\square \\
& R_{t}-I N F_{t}=\alpha_{2}+\beta_{1} E I N F_{t}+\beta_{2} U_{I N F_{t}+\varphi_{2} D_{t}+\text { error }_{t}} \\
& R_{t}-I N F_{t}=\alpha_{3}+\beta_{1} I N F_{t}+\varphi_{3} D_{t}+\text { error }_{t}
\end{aligned}
$$

\begin{tabular}{|c|c|c|c|}
\hline & (1) & (2) & (3) \\
\hline \multirow[t]{2}{*}{ Constant } & 0.88 & 0.77 & $1.62^{*}$ \\
\hline & $(0.76)$ & $(0.68)$ & (1.63) \\
\hline INF $_{t}$ & --- & --- & $-5.51^{\text {**** }}$ \\
\hline$-\cdots$ & --- & & $(2.71)$ \\
\hline \multirow{2}{*}{$\mathbf{E I N F}_{t}$} & -1.86 & -1.76 & --- \\
\hline & $(0.57)$ & $(0.55)$ & --- \\
\hline \multirow[t]{2}{*}{ UINF $_{t}$} & --- & $-8.16^{* * * *}$ & --- \\
\hline & --- & $(3.06)$ & --- \\
\hline \multirow[t]{2}{*}{$\mathbf{D}_{t}$} & 0.31 & 0.43 & 1.18 \\
\hline & $(0.22)$ & $(0.32)$ & $(0.93)$ \\
\hline Adj. $\mathbf{R}^{2}$ & 0.001 & 0.02 & 0.02 \\
\hline
\end{tabular}

Notes: D represents a dummy variable which is set equal to one from September 1979 through December 1990, to account for the significant rise in the inflationary pressures. Instruments employed in the 2SLS estimates are constant, IP, PR, CPI.

** and $* * *$ represent $5 \%$, and $1 \%$ significance levels, respectively.

\section{Inflation and Real Activity}

Table 3(a, b) reports the regression results for equations (4) and (5). Ten lagging/leading and the contemporary values of GIP were initially included in the regressions in panel (A). Akaike's Information Criterion (AIC) was employed to reach an optimal dimension for the GIP. Two sets of regressions are estimated to ensure that statistical significance of coefficients is robust and possibility of multicollinearity is minimized. The estimation results are reported under columns (1: $\mathrm{k}=10)$ and $(2: \mathrm{k}=6)$. Panel $\mathrm{A}$, columns (1) and (2) suggest a negative correlation between real economic activity and inflation rate. One Lagging and several leading (future) values of GIP are statistically significant suggesting a possible negative correlation between inflation and the real economic activity.

Panel B of the Table 3 shows the statistical support for positive relationship between real air transport index returns and real economic activity. The implication is that air transport equity returns and real economic activity are positively correlated. A number of leading and lagging coefficients in Panel B are positive and statistically significant at $\mathrm{k}=6$ and $\mathrm{k}=10$. The evidence thus suggests that real air index returns are weakly related to the real economic activity. To further investigate the lead and lag relationship between these variables, Granger causality tests were conducted. The tests show that the real economic activity and inflation Granger cause air transport equity index and there is also feedback. These results further indicate that there is a relationship between air transport equity index, inflation, and the real economic activity. ${ }^{13}$ In sum, the empirical findings suggest a negative relationship between real returns and inflation and a weak positive relationship between the real economic activity and real index returns. Therefore, when inflationary pressures adversely affect economic activities, they may also adversely affect air transport index returns. The findings reported in Table 3 lend support for Fama's proxy hypothesis. 
Table 3: Testing Propositions A and B hypothesis

\begin{tabular}{|c|c|c|c|c|}
\hline & \multicolumn{2}{|c|}{ Panel A: Inflationary trends and real activity } & \multicolumn{2}{|c|}{ Panel B: Air transport equity returns and real activity } \\
\hline \multicolumn{5}{|c|}{$I N F_{t}=\alpha+\sum_{i=-k}^{k} \beta_{i} G I P_{t+i}+\varphi D_{t}+$ error $_{t} R_{t}-I N F_{t}=\alpha+\sum_{i=-k}^{k} \beta_{i} G I P_{t+i}+\varphi D_{t}+$ error $_{t}$} \\
\hline & $\mathrm{k}=\mathbf{1 0}$ & $k=6$ & $\mathrm{k}=\mathbf{1 0}$ & $k=6$ \\
\hline \multirow[t]{2}{*}{$\alpha$} & $0.279^{* * * *}$ & $0.252^{* * *}$ & 0.581 & $1.828^{*}$ \\
\hline & $(8.58)$ & $(7.75)$ & $(0.48)$ & $(1.69)$ \\
\hline \multirow{2}{*}{ GIP $_{\mathrm{t}-10}$} & -0.002 & --- & 1.139 & --- \\
\hline & $(-0.10)$ & & $(1.40)$ & \\
\hline \multirow[t]{2}{*}{ GIP $_{t-9}$} & -0.027 & --- & -0.159 & --- \\
\hline & $(-1.26)$ & & $(-0.19)$ & \\
\hline \multirow[t]{2}{*}{ GIP $_{\mathrm{t}-8}$} & -0.028 & --- & 0.536 & --- \\
\hline & $(-1.31)$ & & $(0.66)$ & \\
\hline \multirow[t]{2}{*}{ GIP $_{\mathrm{t}-7}$} & -0.023 & --- & 0.373 & --- \\
\hline & $(-1.05)$ & & $(0.44)$ & \\
\hline \multirow[t]{2}{*}{ GIP $_{\mathrm{t}-6}$} & -0.019 & -0.031 & 0.360 & 0.186 \\
\hline & $(-0.83)$ & $(-1.30)$ & $(0.43)$ & $(0.23)$ \\
\hline \multirow[t]{2}{*}{ GIP $_{\mathrm{t}-5}$} & -0.010 & -0.024 & -1.088 & -0.534 \\
\hline & $(-0.45)$ & $(-1.03)$ & $(-1.29)$ & $(-0.67)$ \\
\hline \multirow{2}{*}{ GIP $_{\mathrm{t}-4}$} & 0.001 & -0.010 & $-1.700^{* * *}$ & $-1.572^{* * *}$ \\
\hline & $(0.04)$ & $(-0.45)$ & $(-2.00)$ & $(-1.99)$ \\
\hline \multirow[t]{2}{*}{ GIP $_{t-3}$} & -0.032 & -0.009 & -0.780 & -0.879 \\
\hline & $(-1.39)$ & $(-0.37)$ & $(-0.94)$ & $(-1.08)$ \\
\hline \multirow[t]{2}{*}{ GIP $_{t-2}$} & -0.026 & -0.023 & 1.145 & 0.880 \\
\hline & $(-1.14)$ & $(-0.94)$ & $(1.35)$ & $(1.07)$ \\
\hline \multirow[t]{2}{*}{ GIP $_{t-1}$} & -0.023 & $-0.039^{*}$ & 0.593 & 0.785 \\
\hline & $(-1.03)$ & $(-1.62)$ & $(0.69)$ & $(0.96)$ \\
\hline \multirow[t]{2}{*}{ GIP } & -0.014 & $-0.048^{* * *}$ & --- & -0.330 \\
\hline & $(-0.60)$ & $(-1.96)$ & --- & $(-0.40)$ \\
\hline \multirow[t]{2}{*}{ GIP $_{t+1}$} & -0.010 & -0.030 & -0.701 & -0.361 \\
\hline & $(-0.43)$ & $(-1.21)$ & $(-0.82)$ & $(-0.43)$ \\
\hline \multirow[t]{2}{*}{ GIP $_{\mathrm{t}+2}$} & 0.002 & -0.005 & -0.519 & -0.215 \\
\hline & $(0.08)$ & $(-0.21)$ & $(-0.60)$ & $(-0.26)$ \\
\hline \multirow[t]{2}{*}{ GIP $_{t+3}$} & 0.006 & 0.032 & 0.656 & 0.407 \\
\hline & $(0.27)$ & $(1.28)$ & $(0.78)$ & $(0.48)$ \\
\hline \multirow[t]{2}{*}{ GIP $_{t+4}$} & -0.010 & 0.015 & 1.082 & 0.684 \\
\hline & $(-0.43)$ & $(0.62)$ & $(1.23)$ & $(0.83)$ \\
\hline \multirow[t]{2}{*}{ GIP $_{t+5}$} & 0.028 & 0.006 & -0.698 & -0.700 \\
\hline & $(1.17)$ & $(0.28)$ & $(0.77)$ & $(-0.86)$ \\
\hline \multirow[t]{2}{*}{ GIP $_{t+6}$} & $0.066^{* * * * *}$ & 0.008 & $2.309^{* * * * 2}$ & $1.997^{* * * * *}$ \\
\hline & $(2.62)$ & $(0.34)$ & $(-2.51)$ & $(2.41)$ \\
\hline \multirow[t]{2}{*}{ GIP $_{t+7}$} & $0.045^{* * *}$ & -- & -1.356 & -- \\
\hline & $(1.79)$ & & $(-1.45)$ & \\
\hline GIP $_{t+8}$ & -0.011 & --- & -0.198 & --- \\
\hline & $(-1.24)$ & & $(-0.21)$ & \\
\hline GIP $_{t+9}$ & $-0.076^{* * * *}$ & --- & 1.295 & --- \\
\hline & $(-3.09)$ & & $(1.43)$ & \\
\hline GIP $_{t-10}$ & $-0.084^{* * * * *}$ & --- & $2.471^{* * * *}$ & --- \\
\hline & $(-3.41)$ & & $(2.72)$ & \\
\hline D & $0.138^{* * * *}$ & $0.176^{* * * *}$ & 0.177 & -0.689 \\
\hline & $(4.08)$ & $(4.79)$ & $(0.14)$ & $(-0.56)$ \\
\hline & $\bar{R}^{2}=0.281$ & $\bar{R}^{2}=0.186$ & $\bar{R}^{2}=0.127$ & $\bar{R}^{2}=0.070$ \\
\hline
\end{tabular}

Notes: The lead/lag dimension of the independent variable is determined by the minimum AIC. R= $\log \left(\mathrm{PR}_{t} / \mathrm{PR}_{t-1}\right), \mathrm{GIP}=\log \left(\mathrm{IP}{ }_{t} /\right.$ $\left.\mathrm{IP}_{t-1}\right)$, and $\mathrm{INF}=\log \left(\mathrm{CPI} t_{t} / \mathrm{CPI} t_{t-1}\right)$ measure returns, growth in industrial production, and the inflation rate, respectively. D represents a dummy variable which is equal to one from September 1979 through December 1990, and captures the effects of inflation. $*$,**, and *** represent $10 \%, 5 \%$, and $1 \%$ significance levels, respectively. 


\section{Air Transport Equity Index Returns, Inflation, and Real Activity}

Empirical findings summarized in Table 3 support a weak positive relationship between real air transport index return and real economic activity. The results indicate a negative relation between inflation and real economic activity. The Granger causality tests suggest that real economic activity may be influencing real PR returns by increasing the business demand for air transport services. ${ }^{14}$

\section{Combined Tests}

To further investigate the relationship between real index returns, inflation and the real economic activity, combined tests are performed. To this end, the possible impact of GIP on inflation must first be purged. The purged inflation variable $\left(\xi_{t j}\right.$ ) can then be used in the real index returns regression

$$
R_{t}-I N F_{t}=\alpha+\sum_{i=-k}^{k} \beta_{i} G I P_{t+i}+\theta_{j} \xi_{t j}+\text { error }_{t}, \mathrm{j}=1,2,3 \text {, }
$$

where $\xi_{t j}$ are regression residuals alternatively obtained from

$$
\begin{aligned}
& I N F_{t}=\alpha_{1}+\sum_{i=-k}^{k} \phi_{i} G I P_{t+i}+\xi_{t 1}, \\
& E I N F_{t}=\alpha_{2}+\sum_{i=-k}^{k} \phi_{2} G I P_{t+i}+\xi_{t 2}, \text { and } \\
& U I N F_{t}=\alpha_{3}+\sum_{i=-k}^{k} \phi_{3} G I P_{t+i}+\xi_{t 3} .
\end{aligned}
$$

The results from the alternate estimation of equation (6) are reported in Table 4. The three columns show that after controlling for real economic activity and inflation correlation, there is a strong negative relationship between real returns and the purged inflation variable $\left(\xi_{t j}\right)$, indicating that air transport investment is not a safe haven against inflation. As in Table 2, the negative correlation between real return and purged inflation stems from the unexpected component of the inflation, shown by the significance of the purged inflation variable in columns I and III. The mixed effect of real economic activity and real returns found in Table 3 is also verified. Empirical findings summarized in Table 4 indicate that there is support for the negative relationship between the inflation and real transport index returns. The purged inflation variable is statistically significant in columns I and III (which correspond to total and unexpected inflation rates, respectively). Thus during periods of high inflation, air transport equity returns fall as well. One explanation may be the contestability of the air carrier markets. Competitive pressures by oligopolistic firms in this sector keep fares from rising in the face of rising labor, fuel, and other operating expenses. Recent events in the slowing U.S. economy lend support for this hypothesis. Labor and other operational expenses of some carriers, e.g., United Airlines and U.S. Airways, among others, have driven these carriers to seek Chapter Eleven bankruptcy protection. Furthermore, there are new calls for re-regulation of the U.S. air transport industry. Findings in Table 3 and 4 negate the Fisherian hypothesis and do not lend unequivocal support for the proxy hypothesis. 
Table 4: Real returns, inflation, and real activity

\begin{tabular}{|c|c|c|c|}
\hline \multicolumn{4}{|c|}{ Airline } \\
\hline & I & II & III \\
\hline \multirow[t]{2}{*}{$\alpha$} & 0.779 & 0.621 & 0.786 \\
\hline & $(0.65)$ & $(0.51)$ & $(0.66)$ \\
\hline \multirow{2}{*}{ GIP $_{t-10}$} & 1.192 & 1.327 & 1.323 \\
\hline & $(1.47)$ & $(1.61)$ & (1.64) \\
\hline \multirow[t]{2}{*}{ GIP $_{t-9}$} & -0.111 & 0.121 & -0.042 \\
\hline & $(-0.13)$ & $(0.14)$ & $(-0.05)$ \\
\hline \multirow[t]{2}{*}{ GIP $_{t-8}$} & 0.492 & 0.715 & 0.542 \\
\hline & $(0.60)$ & $(0.87$ & $(0.67)$ \\
\hline \multirow[t]{2}{*}{ GIP $_{t-7}$} & 0.153 & 0.307 & 0.162 \\
\hline & $(0.18)$ & $(0.36)$ & $(0.19)$ \\
\hline \multirow{2}{*}{ GIP $_{t-6}$} & 0.218 & 0.113 & 0.185 \\
\hline & $(0.25)$ & $(0.13)$ & $(0.22)$ \\
\hline \multirow[t]{2}{*}{ GIP $_{t-5}$} & -1.078 & -1.164 & -1.078 \\
\hline & $(-1.28)$ & $(-1.38)$ & $(-1.29)$ \\
\hline \multirow[t]{2}{*}{$\mathbf{G I P}_{t-4}$} & -1.570 & -1.630 & -1.556 \\
\hline & $(-1.85)$ & $(-1.92)$ & $(-1.85)$ \\
\hline \multirow[t]{2}{*}{$\operatorname{GIP}_{t-3}$} & -0.577 & -0.443 & -0.58 \\
\hline & $(-0.67)$ & $(-0.52)$ & $(-0.69)$ \\
\hline \multirow[t]{2}{*}{ GIP $_{t-2}$} & 1.274 & 1.261 & 1.240 \\
\hline & $(1.50)$ & $(1.48)$ & (1.47) \\
\hline \multirow[t]{2}{*}{ GIP $_{t-1}$} & 0.597 & 0.467 & 0.562 \\
\hline & $(0.70)$ & $(0.54)$ & $(0.66)$ \\
\hline \multirow[t]{2}{*}{ GIP } & -1.013 & -1.241 & -1.031 \\
\hline & $(-1.17)$ & $(-1.43)$ & $(-1.20)$ \\
\hline \multirow[t]{2}{*}{ GIP $_{t+1}$} & -0.685 & -0.806 & -0.683 \\
\hline & $(-0.80)$ & $(-0.94)$ & $(-0.80)$ \\
\hline \multirow[t]{2}{*}{ GIP ${ }_{t+2}$} & -0.350 & -0.391 & -0.345 \\
\hline & $(-0.40)$ & $(-0.45)$ & $(-0.40)$ \\
\hline \multirow[t]{2}{*}{ GIP $_{t+3}$} & 0.896 & 1.048 & 0.890 \\
\hline & (1.02) & (1.19) & (1.02) \\
\hline \multirow[t]{2}{*}{ GIP $_{t+4}$} & 1.061 & 1.186 & 1.027 \\
\hline & $(1.21)$ & $(1.35)$ & $(1.18)$ \\
\hline \multirow[t]{2}{*}{ GIP $_{t+5}$} & -0.724 & -0.878 & -0.747 \\
\hline & $(-0.80)$ & $(-0.97)$ & $(-0.83)$ \\
\hline \multirow[t]{2}{*}{ GIP $_{t+6}$} & $2.312^{* * * *}$ & $2.676^{* * * *}$ & $2.325^{* * * *}$ \\
\hline & $(2.45)$ & $(2.83)$ & $(2.50)$ \\
\hline \multirow[t]{2}{*}{ GIP $_{t+7}$} & -1.292 & -1.471 & -1.186 \\
\hline & $(-1.37)$ & $(-1.57)$ & $(-1.27)$ \\
\hline \multirow[t]{2}{*}{$\operatorname{GIP}_{t+8}$} & -0.157 & -0.087 & -0.160 \\
\hline & $(-0.17)$ & $(-0.095)$ & $(-0.17)$ \\
\hline \multirow[t]{2}{*}{$\mathbf{G I P}_{t+9}$} & 1.112 & 1.483 & 1.011 \\
\hline & $(1.20)$ & $(1.63)$ & $(1.10)$ \\
\hline GIP $_{t+10}$ & $2.242^{\text {**** }}$ & $2.680^{\text {***** }}$ & 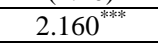 \\
\hline & $(2.40)$ & $(2.92)$ & $(2.34)$ \\
\hline DUM & $0.010^{* * * * *}$ & 0.269 & 0.038 \\
\hline & $(0.008)^{* * * *}$ & $(0.21)$ & $(0.03)$ \\
\hline$\xi$ & -3.780 & 5.828 & $-6.283^{* *}$ \\
\hline & $(-1.41)$ & $(0.98)$ & $(-2.10)$ \\
\hline & $\bar{R}^{2}=0.144$ & $\bar{R}^{2}=0.140$ & $\bar{R}^{2}=0.155$ \\
\hline
\end{tabular}

Notes: $* * *$, and $* * *$ represent $10 \%, 5 \%$, and $1 \%$ significance levels, respectively.

The results are from the equation: 


$$
\begin{aligned}
& R_{t}-I N F_{t}=\alpha+\sum_{i=-k}^{k} \beta_{i} G I P_{t+i}+\theta_{j} \xi_{t j}+u_{t}, \mathrm{j}=1,2,3, \text { where } \xi_{t j} \text { is alternately obtained from } \\
& \text { I. } \xi_{t 1}=I N F_{t}-\alpha_{1}-\sum_{i=-k}^{k} \phi_{i} G I P_{t+i}, \text { II. } \xi_{t 2}=E I N F_{t}-\alpha_{2}-\sum_{i=-k}^{k} \phi_{2} G I P_{t+i} \text {, and } \\
& \text { III. } \xi_{t 3}=U I N F_{t}-\alpha_{3}-\sum_{i=-k}^{k} \phi_{3} G I P_{t+i}, \text { respectively. }
\end{aligned}
$$

\section{Cointegration Tests and Long-run equilibrium}

Given the mixed results for the tests of relationship between air transport equity index returns and real economic activity, tests for the long-run equilibrium relationship among price level, industrial production, and air transport equity index employing Johansen and Juselius (1990) cointegration tests, were performed. Cointegration refers to the possibility that non-stationary variables may have a linear combination that is stationary. Such a linear combination, the cointegrating vector, implies that there is a long-run equilibrium relationship among variables, i.e., variables will not wander off apart from one another over extended periods of time. Therefore, cointegration between the air transport equity index, price levels, and the industrial production implies a long-run relationship between these variables. The test of cointegration employed in this paper is a methodology suggested by Johansen (1988) and Johansen and Juselius (1990). This method is a multivariate generalization of the methodology suggested by Engle and Granger (1987). A brief description of the test is as follows. Let

$\Delta \mathrm{x}_{t}=\sum_{i=1}^{p-1} \Gamma_{i} \Delta x_{t-i}+\pi \mathrm{x}_{t-1}+\varepsilon_{t}$,

where $\mathrm{x}_{t}$ and $\varepsilon_{t}$ are $\left(\mathrm{n}^{* 1} 1\right)$ vectors and $\pi$ is an $(\mathrm{n} * \mathrm{n})$ matrix of parameters. The Johansen (1988) methodology requires estimating the system of equations in (11) and examining the rank of matrix $\pi$. If rank $(\pi)=0$, then there is no stationary linear combination of the $\left\{\mathrm{x}_{i t}\right\}$ process, the variables are not cointegrated. Since the rank of a matrix is the number of non-zero eigenvalues $(\lambda)$, the number of $\lambda>0$ represents the number of cointegrating vectors among the variables. The test for the nonzero eigenvalues is normally conducted using the following two test statistics:

$$
\begin{aligned}
& \lambda_{\text {trace }}(\mathrm{r})=-\mathrm{T} \sum_{i=r+1}^{n} \ln \left(1-\hat{\lambda}_{i}\right) \\
& \lambda_{\max }(\mathrm{r}, \mathrm{r}+1)=-\mathrm{T} \ln \left(1-\hat{\lambda}_{r+1}\right)
\end{aligned}
$$

where $\hat{\lambda}_{i}$ is the estimated eigenvalues, and $\mathrm{T}$ is the number of valid observations. Note that $\lambda_{\text {trace }}$ statistic is simply the sum of $\lambda_{\max }$ statistic. In equation (11), $\lambda_{\text {trace }}$ tests the null hypothesis that the number of distinct cointegrating vectors is less than or equal to $r$ against a general alternative. $\lambda_{\max }$ statistic tests the null hypothesis of $r$ cointegrating vectors against $r+1$ cointegrating vectors. Johansen and Juselius (1990) and Osterwal-Lenum (1992) derive the critical values of $\lambda_{\text {trace }}$ and $\lambda_{\text {max }}$ by simulation method.

Prior to performing the Johansen and Juselius tests, the lag order of the VAR model in the cointegration tests must be determined. The Akaike Infromation Criterion (AIC), the Schwarz Baysian Criterion (SBC), and likelihood 
ratio tests are the basis for the choice of the VAR order. The optimum VAR lag order is selected based on the AIC and SBC, which indicate a lag order $(\mathrm{k})$ of 2 . These findings are reported in Table 5.

The results of various cointegration tests, reported in Table 6 , indicate that there is some evidence suggesting a long-run equilibrium relationship among air transport equity index, inflation, and industrial production. $\lambda_{\text {trace }}$ and $\lambda_{\max }$ tests indicate that there is at least one cointegrating vector among the three variables. There is also evidence that there is a bilateral long-run equilibrium relationship between air transport equity index and consumer price levels, and real economic activity. Furthermore, investigation of the short-term dynamic among the variables under question is warranted.

Table 7 presents the estimated coitegrating vector and its estimation under two restrictions. The restrictions are statistically rejected as reported in columns two and three of the Table. Thus, there is some evidence that in the long run the air transport index is correlated with the general price levels measured by CPI and the industrial activity in the U.S. economy.

The maximum likelihood estimate of the cointegrating vector, subject to the exactly identifying restriction that the coefficient of the PR is equal to one, is given by equation (13) as

$\mathrm{PR}=0.06 \mathrm{IP}-0.42 \mathrm{CPI}+0.32$ Trend,

$(0.03) \quad(0.45) \quad(0.60)$

where the numbers in parentheses are standard deviations.

Equation (13) shows that in the long run the industrial production is positively and significantly correlated with the air transport equity price index. However, the correlation between the index and the CPI is insignificant. Thus, as price levels rise in the long run, the index of air transport equities does not keep pace with it, resulting in falling returns. Therefore, there is no long- run support for the Fisherian hypothesis, and the hypothesis that air transport equity index is a hedge against inflation. The relationship between air transport equity index and the real economic activity in the long run is positive, but weak. This finding is also plausible. Th rising industrial production may indicate a growth in corporate profits. Rising corporate profits often bolster stock prices and stock investments. Thus, from a portfolio point of view, a shift in investments from bonds to air transport equity occurs, raising air transport equity index and boosting equity prices. This scenario has been played out as air transport equity index has lost its allure as an investment vehicle in periods of falling economic activity. Our findings show no long-run empirical evidence in support of the air transport equity index investment as a safe haven inflation hedge in the long run.

Table 5: Test Statistics and Choice Criteria for Selecting the Order of the VAR(12)Model

\begin{tabular}{|c|c|c|c|}
\hline \multicolumn{4}{|c|}{$\begin{array}{c}\text { List of variables included in the unrestricted VAR: PR CPI IP } \\
\text { exogenous variables: Constant DUM TREND }\end{array}$} \\
\hline Order & LL & AIC & SBC \\
\hline 12 & 1558.1 & 1675.1 & 1873.9 \\
\hline 11 & 1569.4 & 1677.4 & 1860.9 \\
\hline 10 & 1576.6 & 1675.6 & 1843.8 \\
\hline 9 & 1587.0 & 1677.0 & 1830.0 \\
\hline 8 & 1590.3 & 1671.3 & 1709.0 \\
\hline 7 & 1600.7 & 1672.7 & 1779.3 \\
\hline 6 & 1609.2 & 1672.2 & 1759.9 \\
\hline 5 & 1614.2 & 1668.2 & 1741.0 \\
\hline 4 & 1619.6 & 1664.6 & 1727.1 \\
\hline 3 & 1629.9 & 1665.9 & $1707.9 * * *$ \\
\hline 2 & 1635.1 & 1662.1 & 1710.1 \\
\hline 1 & 1661.6 & 1679.6 & 2525.6 \\
\hline
\end{tabular}

Notes: $\mathrm{AIC}=$ Akaike Information Criterion $\mathrm{SBC}=$ Schwarz Bayesian Criterion Lag order of 2 for the VAR is recommended by both AIC and SBC criteria. 
Table 6: Long-Term Equilibrium: Johansen-Juselius Maximum Likelihood Procedure Cointegration LR Test Based on Maximal Eigenvalue and Trace of the Stochastic Matrix Variables included in the cointegrating vector

\begin{tabular}{|c|c|c|c|c|c|}
\hline \multicolumn{6}{|c|}{ Panel A: } \\
\hline & & PR\& IP & PR\&CPI & CPI\&IP & CPI\&PR\&IP \\
\hline Но & На & & & $\lambda_{\max }$ & \\
\hline \multirow[t]{3}{*}{$\mathrm{r}=0$} & $\mathrm{r}=1$ & $13.57^{\mathrm{a}^{*}}$ & $8.53^{\mathrm{a}}$ & $14.62^{\mathrm{a}^{*}}$ & $25.22^{\mathrm{a}^{* * 4}}$ \\
\hline & & $17.18^{\mathrm{b}^{*}}$ & $21.61^{\mathrm{b}^{* *}}$ & $14.79^{b}$ & $25.49^{\mathrm{b} * *}$ \\
\hline & & $14.18^{c}$ & $17.81^{\mathrm{c}^{\mathrm{*}}}$ & $9.89^{\mathrm{c}}$ & $19.80^{\mathrm{c}}$ \\
\hline \multirow[t]{3}{*}{$\mathrm{r} \leq 1$} & $\mathrm{r}=2$ & $4.65^{\mathrm{a}}$ & $6.36^{\mathrm{a}}$ & $0.38^{\mathrm{a}}$ & $7.16^{\mathrm{a}}$ \\
\hline & & $6.71^{\mathrm{b}}$ & $6.58^{\mathrm{b}}$ & $9.12^{\mathrm{b}}$ & $9.31^{\mathrm{b}}$ \\
\hline & & $1.41^{\mathrm{c}}$ & $4.32^{\mathrm{c}}$ & $3.18^{\mathrm{c}}$ & $9.26^{\mathrm{c}}$ \\
\hline \multirow[t]{3}{*}{$\mathrm{r} \leq 2$} & $r=3$ & --- & --- & --- & $0.39^{\mathrm{a}}$ \\
\hline & & --- & --- & --- & $7.09^{\mathrm{b}}$ \\
\hline & & & & & $1.96^{\mathrm{c}}$ \\
\hline \multicolumn{6}{|c|}{ Panel B: } \\
\hline & & & & $\lambda_{\text {trace }}$ & \\
\hline \multirow[t]{3}{*}{$\mathrm{r}=0$} & $\mathrm{r} \geq 1$ & $18.22^{\mathrm{a}^{* *}}$ & $14.89^{\mathrm{a}}$ & $15.00^{\mathrm{a}}$ & $32.77^{\mathrm{a}^{* * *}}$ \\
\hline & & $23.87^{b^{* *}}$ & $28.219^{\mathrm{b}^{* * *}}$ & $23.90^{\mathrm{b*}}$ & $42.90^{\mathrm{b}^{* * *}}$ \\
\hline & & $15.60^{\mathrm{a}}$ & $22.13^{\mathrm{c}^{*}}$ & $13.18^{\mathrm{c}}$ & $31.03^{\mathrm{c}}$ \\
\hline \multirow[t]{3}{*}{$\mathrm{r} \leq 1$} & $r \geq 2$ & $4.65^{\mathrm{a}}$ & $6.36^{\mathrm{a}}$ & $0.38^{\mathrm{a}}$ & $7.54^{\mathrm{a}}$ \\
\hline & & $6.71^{\mathrm{b}}$ & $6.58^{\mathrm{b}}$ & $9.12^{\mathrm{b}}$ & $16.40^{\mathrm{b}}$ \\
\hline & & $1.41^{\mathrm{c}}$ & $4.32^{\mathrm{c}}$ & $3.18^{c}$ & $11.22^{\mathrm{c}}$ \\
\hline \multirow[t]{3}{*}{$\mathrm{r} \leq 2$} & $r=3$ & --- & --- & --- & $0.39^{\mathrm{a}}$ \\
\hline & & --- & --- & --- & $7.09^{\mathrm{b}}$ \\
\hline & & & & & $1.96^{\mathrm{b}}$ \\
\hline
\end{tabular}

Notes: CPI, IP and PR stand for the consumer price index, industrial production index, and Air transport equity price. $\mathrm{r}$ stands for the number of cointegrating vectors. Critical values are taken from Oterwald-Lenum (1992).

a. Unrestricted intercepts and no trends in the $\operatorname{VAR}(2)$.

b. Unrestricted intercepts and restricted trend in the VAR(2).

c. Unrestricted intercepts and unrestricted trend in the VAR(2).

The lag number in VAR=2 is based on the Akaike and Schwarz criteria. Eigenvalues of the stochastic matrix are computed and available, but not reported. The hypothesis of $\mathrm{r} \leq 1$ is accepted.

$*$ and $* *$ represent $10 \%, 5 \%$, significance levels, respectively.

Table 7: Estimated Cointegrated Vectors in Johansen Estimation (Normalized in Brackets)

Cointegration with unrestricted intercepts and no trends in the $\operatorname{VAR}(2), r=1$.

\begin{tabular}{|c|c|c|c|}
\hline \multicolumn{3}{|c|}{ List of variables included in the cointegrating vector: PR, IP, CPI, trend } \\
\hline & 1.00 & -0.007 & -0.008 \\
\hline PR & & & $(-1.00)$ \\
\hline & $(--)$ & & $0.68 \mathrm{E}-3$ \\
\hline IP & -0.057 & 0.00 & $(0.08)$ \\
\hline & $(0.031)$ & $(0.00)$ & 0.00 \\
\hline CPI & & & $(0.00)$ \\
\hline & 0.42 & -0.009 & -0.002 \\
\hline Trend & $(0.45)$ & $(-1.17)$ & $(-0.26)$ \\
\hline & -0.32 & 0.01 & $(1.37)$ \\
\hline
\end{tabular}

Notes: $\chi^{2}$ tests the hypotheses that the coefficients of IP and CPI in the cointegraing vector are zero, respectively. * and ***represent 10 and 1 percent significance level. 
To examine the short-run dynamics implied by the cointegrating relationship, the error correction model (ECM) is estimated and reported in Table 8. The error correction model shows a significant F statistic and no first order autocorrelation. The error correction variable (ecm1) is negative and statistically significant. This indicates that air transport equity index adjust to changes in the CPI and IP. Indeed the coefficients of the lagged values of PR are statistically significant supporting the hypothesis that air transport equity index follow changes in the inflation. The absolute value of the error correction coefficient is relatively small (0.03) showing that the speed of this adjustment may be slow. This may be the reason why air transport index investments are not a reliable hedge against inflationary ravages.

Table 8: ECM for variable PRAS estimated by OLS based on cointegrating VAR(2) Dependent variable is dPRAS

\begin{tabular}{|c|c|c|c|}
\hline Regressor & Coefficient & Standard Error & T-Ratio \\
\hline Intercept & $1.731^{k * k}$ & 0.856 & -2.02 \\
\hline $\mathrm{dPR} 1$ & $0.123^{* * *}$ & 0.066 & 1.90 \\
\hline $\mathrm{dIP} 1$ & 0.008 & 0.010 & 0.86 \\
\hline dCPI1 & -0.086 & 0.193 & -0.45 \\
\hline ecm1(-1) & $-5.084^{\text {***k }}$ & 2.319 & -2.19 \\
\hline $\mathrm{R}^{2}=\quad 0.04$ & & & \\
\hline $2.03^{*}$ & & & \\
\hline $\mathrm{DW}=\quad 1.96$ & & & \\
\hline $\mathrm{LL}=\quad-1718.1$ & & & \\
\hline
\end{tabular}

\section{SUMMARY AND CONCLUSIONS}

This paper has investigated the relationship between real air transport equity index returns and inflation. The objective was to establish whether an air transport equity index provides a reliable hedge against inflation. Past studies have shown that real economic activity and the demand for equities and commodities have been negatively affected by rising inflationary pressures. This present research supports a negative relationship between the inflation and real air transport equity index returns, thus negating the Fisherian hypothesis for the index under study. The results also show that real air transport equity index returns are significantly and negatively related to the unexpected inflation, but are not affected by the expected inflation rate. Given that air carriers often have long-term contracts with their labor unions, the effects of unexpected inflation may be felt on the costs of fuel, labor, and meals. Furthermore, pilots, flight attendants, and mechanics unions often renegotiate contracts before contracts expire. The finding suggests that airfares are insensitive to expected rises in general price levels. The negative relationship between the real air transport equity index returns and the price level persists even after the negative affects of the inflation on the real activity is purged. Therefore, real air transport equity index returns may be negatively affected by inflation because of the unexpected inflationary pressures. These results indicate that air transport equity index investment does not provide a viable hedge against inflation. Furthermore, both the Fisherian and the proxy hypotheses are rejected by our statistical findings.

The long-run inflation hedging potential of air transport equity investments is also questionable, as evidenced by estimates of the cointegrating vector. The short-run dynamics derived from the long-run equilibrium relationship between air transport equity index, price levels, and the real economic activity further bolster the notion that air transport equity index adjusts quite slowly to inflationary trends. These results do not lend support for the role of air transport equity index as a long-run inflation hedge. 
It is hoped that these findings may be of use to many different constituencies including portfolio managers, interested investors, airline management and labor, lenders, governmental policy makers and regulators of this vital but stressed industry.

\section{REFERENCES}

1. Adrangi, B., G. Chow and K. Raffiee (1996), Passenger Output and Labor Productivity in the U.S. Airline Industry: A Profit Function Approach, Logistics and Transportation Review, pp. 389-407.

2. Adrangi, B, G. Chow and K. Raffiee (1999), The Effect of Market Structure and Technology on Airline Fleet Composition after Deregulation, Review of Industrial Organization, pp. 77-88.

3. $\quad$ Barnes, M., J.H. Boyd and B.D. Smith (1999), Inflation and Asset Returns, European Economic Review, 43, pp. 737-754.

4. Boudoukh, J. and M. Richardson (1993), Stock Returns and Inflation: A Long-Horizon Perspective, American Economic Review, 83 (5), pp. 1346-1355.

5. Barro, R. J. (1990), Macroeconomics, Third edition, New York: John Wiley and Sons Inc.

6. Berndt, E. R. (1991), The Practice of Econometrics: Classic and Contemporary, Addison- New York: Wesley Publishing.

7. Christie-David, R., M. Chaudhry, and T. Koch (2000), Do Macroeconomics News Releases Affect Gold and Silver Prices? Journal of Economics and Business, Vol. 52, pp. 405-21.

8. Dickey D. A. and W. A. Fuller (1979), Distribution of the Estimators for Autoregressive Time Series with a Unit Root, Journal of the American Statistical Association, 74, pp. 427-31.

9. Ely, D.P. and K.J. Robinson (1997), Are Stocks a Hedge Against Inflation ? International Evidence Using a Long-Run Approach, Journal of International Money and Finance, 16 (1), pp. 141-167.

10. Engle, R. F. and C. W.J. Granger (1987), Co-integration and Error-Correction: Representation, Estimation, and Testing, Econometrica, 55, pp. 251-76.

11. Fama, E. F. (1981), Stock Returns, Real Activity, Inflation and Money, American Economic Review, 71, pp. 545-65.

12. $\quad$----- (1982), Inflation, Output and Money, Journal of Business, 55, pp. 201-31.

13. ------- and M. R. Gibbons (1980), Inflation, Real Returns, and Capital Investment, Working Paper no. 41, Center for Research in Security Prices, Graduate School of Business, University of Chicago.

14. Fama, E.F. and G.W. Schwert (1977), Asset Returns and Inflation, Journal of Financial Economics, 5, pp. 115146.

15. Feldstein, M. (1980a), Inflation and the Stock Market, American Economic Review, 70, pp. 39-47.

16. $\quad$----- (1980b), Inflation Tax Rules, and the Prices of Land and Gold, Journal of Public Economics, Vol. 14, pp. 309-17.

17. Fisher, I. (1930), The Theory of Interest, Ed. Macmillan, New York.

18. Geske, R. and R. Roll, (1983), The Fiscal and Monetary Linkages Between Stock Returns and Inflation, Journal of Finance, 38: pp. 49-65.

19. Gultekin, N.B. (1983), Stock Market Returns and Inflation: Evidence from Other Countries, Journal of Finance, 38 (1), pp. 49-65.

20. Greene, W.H. (1993), Econometric Analysis, 2nd Edition, Macmillan, New York.

21. Hodrick, R. J. and E. C. Prescott (1980), Postwar U.S. Business Cycles: An Empirical Investigation, Discussion Paper 451, Carnegie-Mellon University.

22. International Finance Corporation (1997), Emerging Stock Markets Factbook 1997, Washington, D.C., USA.

23. Jaffe, J. F. and G. Mandelker (1979), Inflation and the Holding Period Returns on Bonds, Journal of Financial and Quantitative Analysis, 14, pp. 959-79.

24. Johansen, S. (1988), Statistical Analysis of Cointegration Vectors, Journal of Economic Dynamics and Control, 12, pp. 231-54.

25. Johansen, S. and K. Juselius (1990), Maximum Likelihood Estimation and Inference on Cointegration With Application to Demand for Money, Oxford Bulletin of Economics and Statistics, 52, pp. 169-210.

26. Kolluri, B. R. (1981), Gold as Hedge Against Inflation: An Empirical Investigation, Quarterly Review of Economics and Business, 4, pp. 213-24. 
27. Kyland, F. E. and E.C. Prescott (1990), Business Cycles: Real Facts and Monetary Myth, Federal Reserve Bank of Minneapolis, Quarterly Review, 3-18.

28. Larson, Alan B. and G.R. McQueen (1995), REITS, Real Estate, and Inflation: Lessons from the Gold Market, Journal of Real Estate and Economics, 10, pp. 285-97.

29. Lintner J. (1975), Inflation, and Security Returns, Journal of Finance, 30, pp. 259-80.

30. Mahdavi, S. and S. Zhou (1977), Gold and Commodity Prices as Leading Indicators of Inflation: Tests of Long-Run Relationship and Predictive Performance. Journal of Economics and Business, 49, pp. 475-89.

31. Mortley, B. (September 1993), Growth and Inflation: a Cross - Country Stud, Federal Reserve Bank of San Francisco.

32. Nelson, C. R. (1976), Inflation and Rates of Return on Common Stocks, Journal of Finance, 13, pp. 478-83.

33. Newey, W., and K. West (1987), A Simple Positive-Definite Heteroscedasticity and Autocorrelation Consistent Covariance Matrix. Econometrica, 55, pp. 703-708.

34. Olesen, J.V., (March 2000), Stocks Hedge against Inflation in the Long Run: Evidence from a Co-integration Analysis for Denmark, Working paper 6-2000, Department of Economics, Copenhagen Business School, Denmark.

35. Osterwald-Lenum, M. (1992), A Note with Quintiles of the Asymptotic Distribution of the Maximum Likelihood Cointegration Rank Test Statistics. Oxford Bulletin of Economics and Statistics, 54, pp. 461-471.

36. Perron, P. (1988), Trends and Random Walks in Macroeconomic Time Series: Further Evidence from a New Approach, Journal of Economic Dynamics and Control, 12, pp. 297-332.

37. Phillips, P.C., and P. Perron (1990), Testing for a Unit Root in Time Series Regression, Biometrika, 75, pp. $335-46$.

38. Serletis, A. (1993), Money and Stock Prices in the United States, Applied Financial Economics, 3, pp. 51-54.

39. Thornton, J. (1993), Money, Output, and Stock Prices in the UK: Evidence on Some Relationships, Applied Financial Economics, 3, pp.335-38.

40. Wahlroos, B. and T. Berglund (1986), Stock Returns, Inflationary Expectations and Real Activity, Journal of Banking and Finance, 10, pp. 377-89.

\section{ENDNOTES}

${ }^{1}$ The Fisherian hypothesis, maintains that real returns in efficient markets are determined by real variables such as capital productivity and are unrelated to nominal variables such as inflation, money supply, etc. For more on this see Fisher (1930).

${ }^{2}$ Mortley (1993) provides evidence from the U.S. economy that persistent inflation could lower the real GDP growth. The theoretical foundations of the proxy effect are detailed in Fama (1980).

${ }^{3}$ The resulting negative relationship between the stock returns and inflation is referred to as the "proxy effect," in the sense that it reflects the detrimental consequence of inflation on real economic activity. Fama argues that the proxy effect vanishes when real activity does not fall because of inflation. Fama and Schwert (1977), however, find that a number of other assets such as the U.S. government bonds and bills and real estate constitute a hedge against inflation.

${ }^{4}$ In a three part series, the Nightly Business Report presented an excellent analysis of the current and predicted future state of affairs in the air transport business November 19-21, 2002. United Airlines is trying to negotiate cost reductions with its labor unions within the protection of a Chapter 11 filing. US Airways is also once again under chapter 11 protection, after having file and existed that protection earlier. Delta Airlines has created its own low cost carrier, Song, to service certain routes. And the hub-and-spoke model so dominant in the industry since the mid 1980s is giving way to rolling hub model introduced by American Airlines. This system is expected to reduce the cost of gate in one hub and keep crews flying more than the previous hub- and -spoke system. Finally, carriers are trying to morph into Southwest clones to further reduce operating costs. The most successful example is American West whose costs per ASM have been reduced from the nearly $\$ .11$ to the low \$.07 Southwest-like range. 
${ }^{5}$ For more on Phillips Curve see Macroeconomics by Robert Barro (1990), pp. 46-474.

${ }^{6}$ The de jure deregulation of the industry commenced with the passage of the Airline Deregulation Act of 1978. The de facto deregulation had actually started in the mid-1970. Therefore, this study covers a period of free market system in the industry. Our data covers through 1998 in order to avoid the industry turmoil of 1999 through the post September 11 period. Some of the problems of the 1990s are related to the hub-and-spoke system adopted by major carriers in the mid 1980s. The business model has been somewhat debunked in the U.S. by the exceptional success of carriers such as the Southwest Airlines.

${ }^{7}$ The index of air transport equities is taken from the Compustat database.

${ }^{8}$ The hedging property is satisfied if the equality sign hold strictly in equations (1) through (3).

${ }^{9}$ The index of air transport equities is taken from the Compustat database.

${ }^{10}$ The hedging property is satisfied if the equality sign hold strictly in equations (1) through (3). The inequality signs indicate strong hedging ability in the sense that investors in this sector would be more than compensated for inflation.

${ }^{11}$ In addition to Fama and Schwert (1977), Gultekin (1983), and Kaul (1987) find that equities are not a hedge against inflation. A number of researchers attempt to find explanations for these findings, notably Feldstein (1980), Fama (1981), and Geske and Roll (1981).

${ }^{12}$ In the presence of autocorrelation and heteroscedasticity it is crucial to obtain unbiased estimator of the coefficient standard errors. For more information on this subject see Greene (1993).

${ }^{13}$ Inflation rate, its expected, and unexpected components are tested for the possibility of being endogenous employing Hausman test (see Berndt (1991), p. 379). The coefficients of the predicted measures of inflation are insignificant in equation (1), showing that inflation rate, and its predicted and unexpected components are not endogenous. Similar tests show that GIP is not endogenous in equations (5) through (8). These results are not reported, but available from the authors.

${ }^{14}$ It is now widely recognized that all decompositions are statistical, and therefore there are an infinite number of ways to decompose a series into permanent and transitory components. An advantage of HP method is that it relies on a minimum number of assumptions and, hence, is more defensible (e.g. Kyland and Prescott (1990)). We select the value of $\theta=14400$ for monthly data, as suggested by Hodrick and Prescott (1980).

${ }^{15}$ Estimated VAR models and Granger causality tests show that real economic activity and CPI Granger causes air transport equity index there is also feedback. These findings are not reported here, but are available from the authors.

${ }^{16}$ Granger causality results are not reported but are available from the authors. 